\title{
Direct observations of clustering (schooling and swarming) behaviour in mysids (Crustacea: Mysidacea)
}

\author{
D. P. O'Brien \\ Zoology Department, University of Tasmania, GPO Box 252C, Hobart, Tasmania 7001, Australia
}

\begin{abstract}
A new scheme is presented for the classification of mysid aggregations according to the mechanisms stimulating their formation and maintenance. Previous classifications were inadequate in simply and effectively describing the social behaviour of 6 species of mysids commonly found in the sublittoral zone off the east coast of Tasmania. All the species observed exhibit clustering behaviour which under the present scheme is defined as: individuals of all stages (although generally segregated) are distributed in integrated aggregations at least during daylight in response to internal biological mechanisms. Cluster form is flexible and subject to both intrinsic and extrinsic factors. Clusters display features of swarming, schooling and shoaling behaviour and a high level of integration between individuals. Evidence for the intrinsic nature of clustering behaviour in mysids is discussed and extrinsic factors are described as periodically influencing the form of the aggregative behaviour. The functions of clustering include increased reproductive potential, antipredation, and maintenance of position in the environment; however, the latter is the most important factor influencing variation in clustering behaviour. Maintenance of position varies with substrate attraction and hydrographic conditions, and the adaptive significance of the different forms of clustering behaviour employed by species in the present study is discussed.
\end{abstract}

\section{INTRODUCTION}

Clutter (1969), in his review of the social organisation of swarming mysids, proposed 4 general functions of this behaviour: to maintain position within a preferred habitat, to reduce predation, to increase reproductive success, and/or to contribute to population regulation. In subsequent papers relating to mysid behaviour, attempts have been made to categorise the social organisation of individual species according to generalised schemes (Mauchline 1971, Wittman 1976). The scheme proposed by Mauchline (1971) was an attempt to classify morphological and behavioural variation in mysid aggregations, in terms of both their internal organisation and the possible biological mechanisms mediating aggregative behaviour (e.g. reproduction). He incorporated terms proposed by Clutter (1969), following direct observations of mysids inhabiting the same region of the subtidal zone as did species observed during the present study. Wittman (1976) redefined 'swarm', 'school', and 'aggregation' and added new terms, basing his definitions primarily on geometric form and secondarily on social interaction. Further- more, he stated that his observations at Strundjan Bay ( $N$ Adriatic Sea) showed that in bright light swarming in mysids is influenced by species-specific attraction to the substrate, and he proposed a broad spectrum based on substrate attraction ranging from substrate-specialists which do not swarm, to swarm specialists whose behaviour is independent of the substrate

The purpose of the present article is to describe the characteristics of aggregative behaviour in the more common species of Tasmanian mysids, chosen for their continuous schooling and swarming behaviour in the field during daylight, and apparent differences in both their attraction to the substrate and the numbers of individuals in the aggregations. Emphasis is placed on relating differences in the schooling/swarming habit of the species to their ecological niche, pre-supposing that social organisation is biologically induced and that any variability in the form of this organisation is due to species-specific adaptation to the environment. An attempt is made to classify the swarming habit of the species using the aforementioned schemes, and the advantages and problems involved in the current definition are discussed. 


\section{MATERIALS AND METHODS}

The taxonomy of the species used in the present study has been outlined by Fenton (1985) with Tenagomysis sp. referring to Tenagomysis sp. 2 nov. $\mathrm{sp}$. and Doxomysis sp. referring to Doxomysis sp. 1 nov. $\mathrm{sp}$.

Terms describing aggregations, e.g. swarm, school, shoal, aggregation, are as defined by Mauchline (1971). A new term 'cluster' refers to those species which normally form integrated aggregations during daylight in response to internal biological mechanisms. Reasons for choosing this particular term and the basis and function of the definition in describing zooplankton aggregations are discussed later.

All observations were recorded in both the field and the laboratory using writing slates or the following camera equipment: (1) a Canon F1 camera with either a $50 \mathrm{~mm}$ macro lens or a $24 \mathrm{~mm}$ wide angle lens (in an Ikelite housing for underwater use); (2) $16 \mathrm{~mm}$ cinematographic film, shot underwater using a Canon Scoopic in an aluminium housing; and (3) the movement of individuals within swarms in the laboratory was recorded on videotape using a JVC GX-N7E video camera suitable for use at low light levels (ca 10 lux).

Current velocity in the field was measured by timing the rate of movement of neutral buoyancy markers past a reference measure such as a weighted rule or set of pre-calibrated points in the immediate vicinity. All references to boulders or boulder regions are to rocks and boulders which protruded at least $0.5 \mathrm{~m}$ above the substrate. All laboratory-based observations described in the following account refer to swarms/schools exhibiting the same behaviour and morphology as those observed in the field under comparable conditions of light intensity (to the human eye) and current.

Test organisms were collected using SCUBA equipment and hand nets (mesh size $1 \mathrm{~mm}^{2}$ ), with care being taken not to cause them any mechanical damage. Collection sites around southeast Tasmania are shown in Fig. 1. Mysids were transported to the laboratory in black plastic containers (20 l capacity) and transferred immediately on arrival to either rectangular holding aquaria $(1 \times 1 \times 0.3 \mathrm{~m})$ or an experimental flume (O'Brien et al. 1986). They were then acclimated to laboratory light conditions for a period of no less than $3 \mathrm{~h}$.

\section{RESULTS}

\section{Cluster population structure}

Composition of mysid aggregations sampled over the study period is described by O'Brien (1987). From this

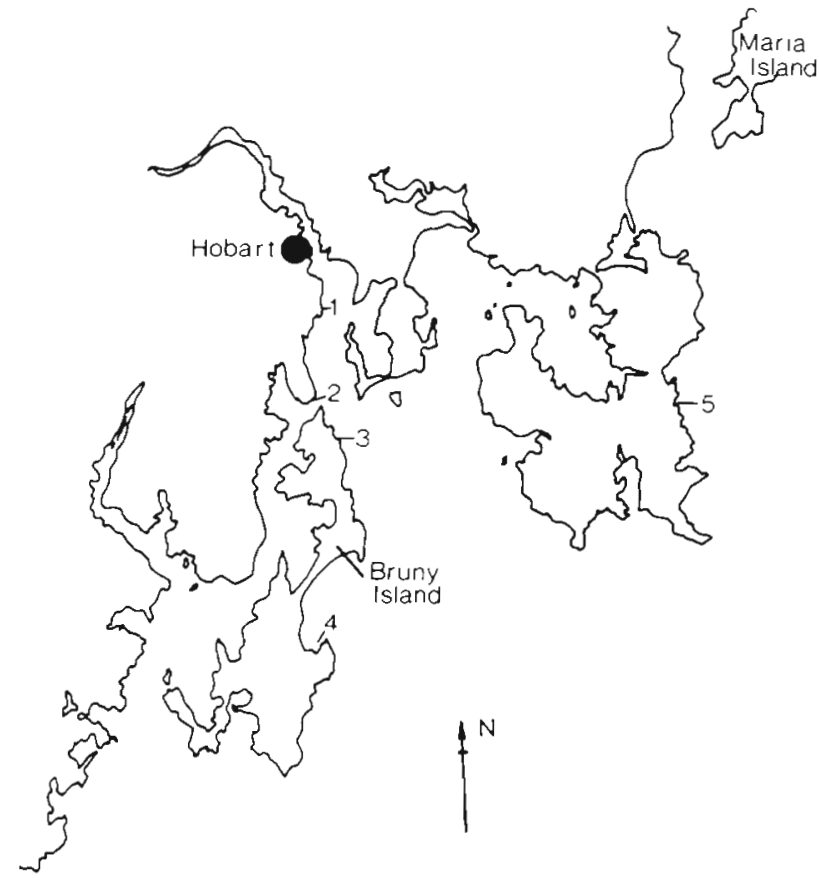

Fig. 1. Major mysid observation and sampling sites in southeast Tasmania. 1: Taroona Beach; 2: Tinderbox; 3: One Tree Point (used in the study by Fenton 1985); 4: Adventure Bay; 5 : Waterfall Bay

data and extensive observations of aggregations of all the species described the major features of cluster population structure were as follows. (1) Apart from Doxomysis sp, all clusters consisted generally of individuals at a similar stage of maturity (i.e. large or small adults, or juveniles). For the purposes of this study observations were concentrated on adult clusters. (2) Male:female ratios were variable for all the species sampled; however, no single sex aggregations were found and the majority of aggregations of all species had approximately equal numbers of both sexes (40 to $60 \%$ males). (3) All species were reproductively active to some degree throughout the year. Doxomysis sp., Tenagomysis sp. and Paramesopodopsis rufa populations all had large proportions of ovigerous females throughout the year with no indication of any seasonal peaks in reproduction; however, Anisomysis mixtaaustralis showed some indication of increased reproductive activity in late summer (February-March). Table 1 shows monthly ranges in the percentage of ovigerous females of each species in clusters. (4) Clusters of aduits occurred throughout the year, although at certain sites the numbers of Paramesopodopsis rufa and Tasmanomysis oculata fluctuated dramatically for periods of up to $1 \mathrm{mo}$ 
Table 1. Percentage range of ovigerous females of Anisomysis mixta-australis, Doxomysis sp., Paramesopodopsis rufa and Tenagomysis sp. for each month of the year. All juveniles: all clusters sampled during these months were composed solely of juveniles; nd: no data available

\begin{tabular}{|c|c|c|c|c|}
\hline \multirow[t]{2}{*}{ Month } & \multicolumn{4}{|c|}{ Species } \\
\hline & $\begin{array}{l}\text { Anisomysis } \\
\text { mixta-australis }\end{array}$ & Doxomysis sp. & $\begin{array}{l}\text { Paramesopodopsis } \\
\text { rufa }\end{array}$ & Tenagomysis sp. \\
\hline $\operatorname{Jan}$ & $18-44$ & nd & 100 & $92-100$ \\
\hline Feb & $67-100$ & 44 & $54-83$ & $85-89$ \\
\hline Mar & $73-78$ & 70 & nd & 67 \\
\hline Apr & All juveniles & 67 & 95 & 66 \\
\hline May & All juveniles & 38 & 100 & $86-90$ \\
\hline Jun & All juveniles & $50-81$ & $0-60$ & $71-87$ \\
\hline Jul & $0-50$ & $67-70$ & $15-67$ & $67-93$ \\
\hline Aug & $25-27$ & $50-90$ & 79 & 87 \\
\hline Sep & 47 & $56-60$ & nd & 83 \\
\hline Oct & 13 & nd & nd & $85-86$ \\
\hline Nov & 26 & 57 & $44-100$ & $71-90$ \\
\hline Dec & $0-88$ & 88 & nd & 62 \\
\hline
\end{tabular}

Fig. 2. Diagrammatical representation (side-view) of the distribution of mysids in situ, in relation to substrate type, form and topography. a: algae on rock outcrop or unconformity; b: more extensive growth of algae on relatively flat rock substrate. 1: Tenagomysis sp.; 2: Doxomysis sp.: 3: Paramesopodopsis rufa; 4: Anisomysis mixta-australis; 5: Tasmanomysis oculata; 6: Australerythrops paradicei
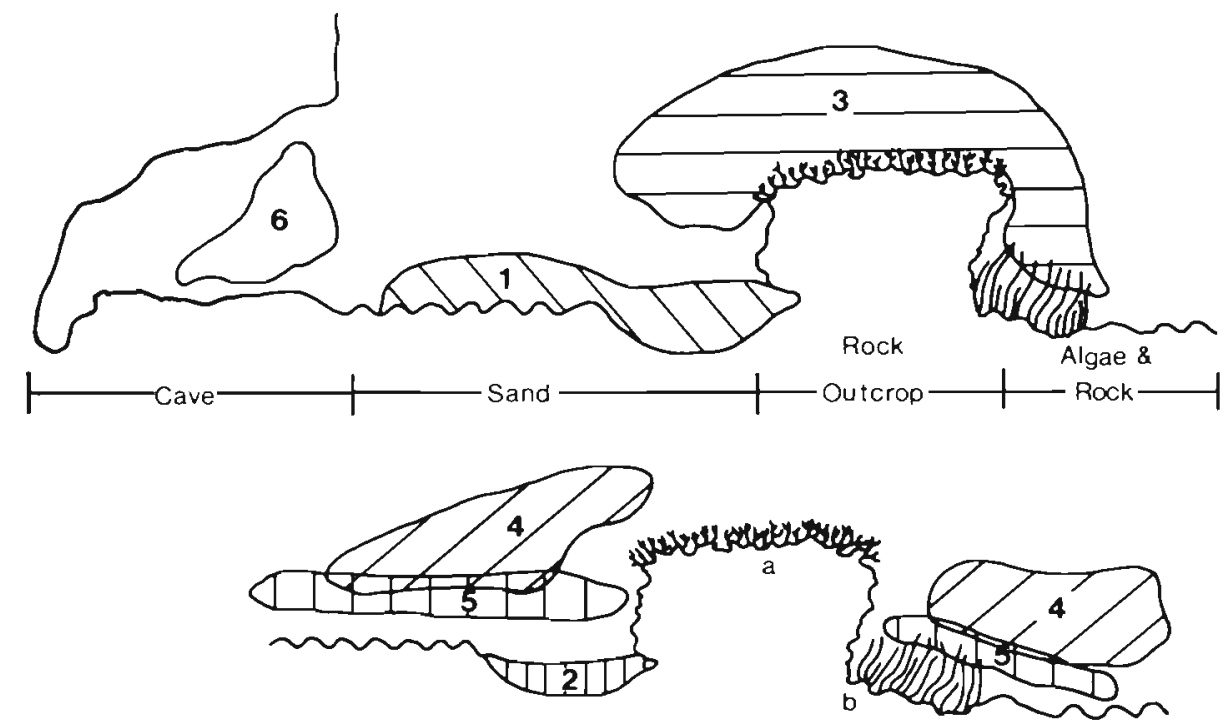

\section{General descriptions of clustering behaviour}

Fig. 2 shows the approximate distribution of each species relative to sea-floor topographical irregularities and distance from the substrate. Table 2 summarises the general cluster characteristics, dimensions, depth ranges and feeding habits for the species studied.

\section{Paramesopodopsis rufa}

Paramesopodopsis rufa is widely distributed around the coast of Tasmania and was generally found around algal-covered rocky outcrops, but not associated with any particular substrate type. Clusters were also located over algal beds, usually located in breaks between algal fronds. During calm conditions P. rufa formed ovoid clusters maintaining the same approximate distribution for extended periods $(>24 \mathrm{~h}$ ), with some clusters apparently being located around the same rock for more than $1 \mathrm{wk}$. However, there was no direct evidence that either the individuals or the cluster remained the same over this period. Little polarization was observed in undisturbed clusters (Fig. $3 \mathrm{~A}$ ), although when there were pronounced axes to the cluster the numbers of individuals oriented parallel to the longest axis also increased. Disturbances such as low velocity currents (2 to 5 $\mathrm{cm} \mathrm{s}^{-1}$ ), vibrations or an attack by a predator caused the individuals to become polarized (Fig. 3 B). Cluster shape was varied, ranging from cigar-shaped to dis- 


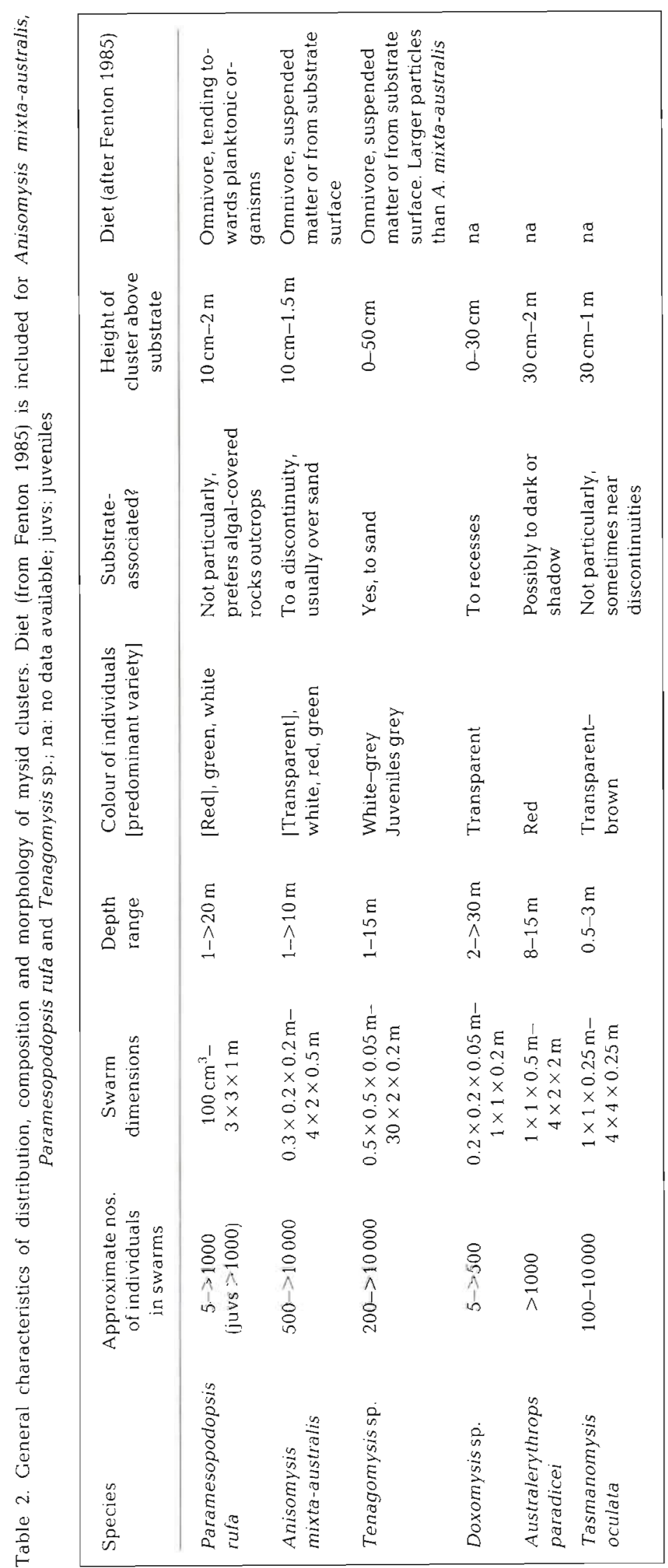



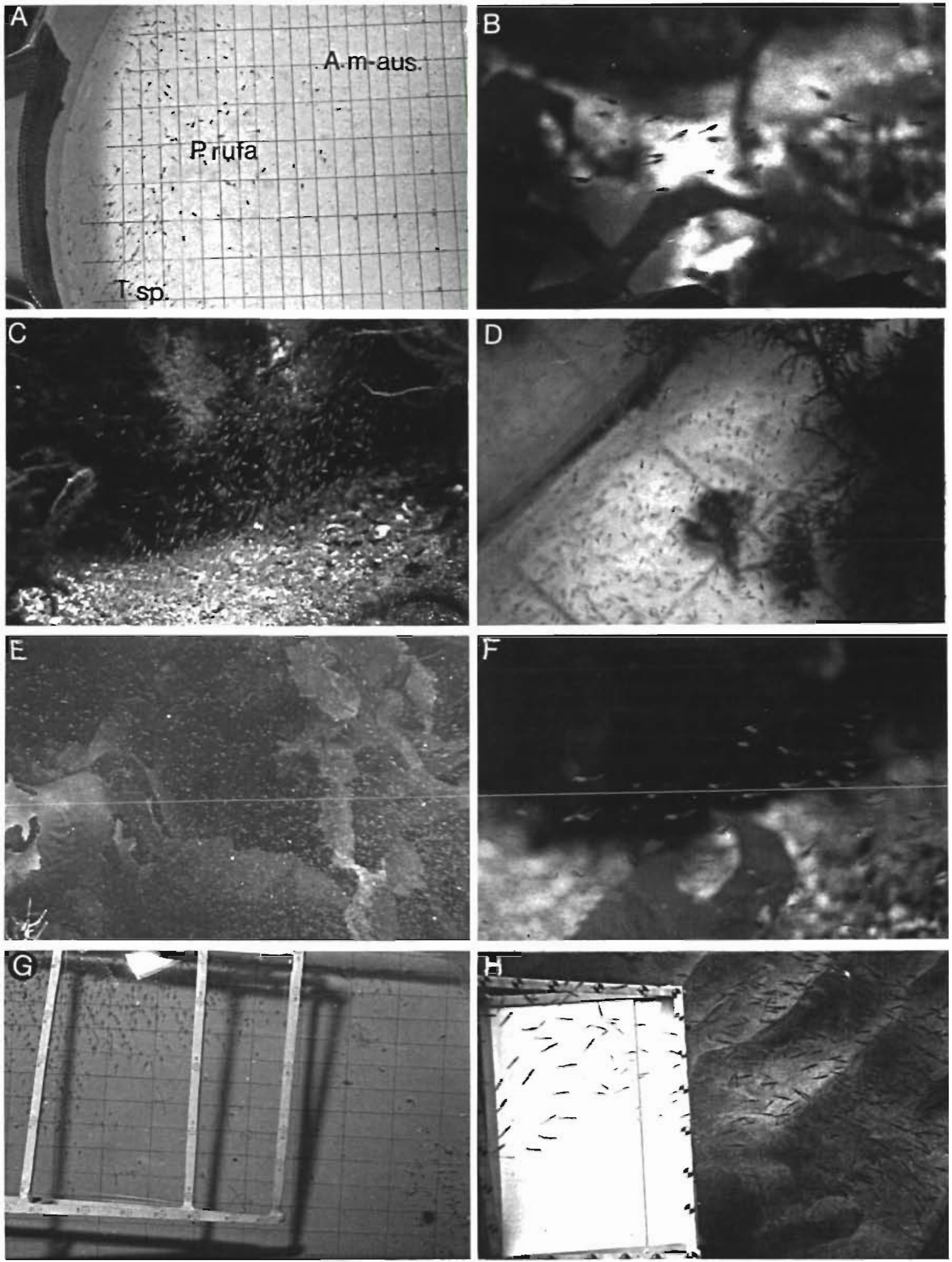

Fig. 3. Mysid clusters as observed in the laboratory (A, D, G) and in the field (B, C, E, F, H). (A) Segregation of Anisomysis mixtaaustralis, Paramesopodopsis rufa and Tenagomysis $\mathrm{sp}$. in the flume, at low current velocity $\left(<3 \mathrm{~cm} \mathrm{~s}^{-1}\right)$; (B) Paramesopodopsis rufa, polarized; (C) Tenagomysis sp., polarized; (D, E) A. mixta-australis, polarized in both the laboratory and in the field; (F) Doxomysis sp., polarized; (G) Australerythrops paradicei, polarized into current; $(\mathrm{H})$ Tasmanomysis oculata, polarized 
coid/ovoid forms (O'Brien unpubl.), depending upon prevailing conditions.

In the field Paramesopodopsis rufa maintained social/aggregative behaviour down to light intensities at which the clusters could no longer be observed by diver without artificial illumination. Night-time observations indicated that individuals maintained the same approximate distribution relative to rock outcrops and algae, although closer to the algae than in daylight. There was also evidence for polarization and cluster integrity during the dark (O'Brien 1987). The mechanisms for polarization during darkness were not identified, although there was some evidence that mysids were oriented into the current produced by incoming/ outgoing waves, and for a collective avoidance of the light source if shone directly at a cluster.

The major features of aggregative behaviour under laboratory conditions included the following. (1) In glass aquaria clusters generally avoided the sides of the tank $\mathrm{k}_{i}$ in the flume they aggregated closer to visual unconformities such as the retainers $\left(\mathrm{O}^{\prime}\right.$ Brien et al. 1986) and patches of different colours on the walls. Clusters tended to be distributed around clumps of algae in otherwise bare aquaria, usually 5 to $10 \mathrm{~cm}$ above and/or to the side of the algae. (2) Clusters became polarized in water currents, orienting directly into the strongest currents. Any sudden decrease/ increase in light intensity in the vicinity of the aquarium increased the degree of polarization in clusters and sometimes produced a disturbance or avoidance reaction. Total polarization of all individuals in the cluster was generally maintained for a period of 5 to $10 \mathrm{~s}$ if the stimulus was not maintained or repeated. After this brief reaction the individuals usually resumed their previous distribution and under calm conditions gradually became depolarized. With repeated disturbance of the cluster (e.g. 5 to $30 \mathrm{~min}$ of periodic changing of light source or passing a hand over the flume), clusters progressively condensed, becoming more polarized and restricted in their distribution for extended periods, i.e. $>10 \mathrm{~min}$. If the light regime was uneven clusters concentrated in regions of greatest intensity. However, clusters oriented into the current usually remained in the region of strongest flow. (3) Clusters maintained their integrity for at least $14 \mathrm{~d}$ in aquaria. (4) Cluster boundaries during still conditions were maintained because individuals, on reaching the periphery, immediately turned back into the cluster. At low current velocities $\left(<5 \mathrm{~cm} \mathrm{~s}^{-1}\right.$ approx.) the individuals swam towards the front of the cluster and on reaching the front margin turned back (usually dropping back passively with the current) into the main body of the cluster and recommenced swimming towards the front. In stronger currents $(>5$ to $10 \mathrm{~cm} \mathrm{~s}^{-1}$ approx.) the individuals maintained their position in the cluster for extended periods ( $>1 \mathrm{~min}$ ). Individuals in non-polarized clusters swam constantly in what appeared to be random directions within the boundaries of the cluster. Evidence for integration within these non-polarized clusters was demonstrated by the fact that there were no collisions between individuals, and pairs of individuals showed a form of attraction manifested in concerted changes in direction over short periods $(<5 \mathrm{~s})$. There was no evidence for any form of leadership within clusters. Video analyses
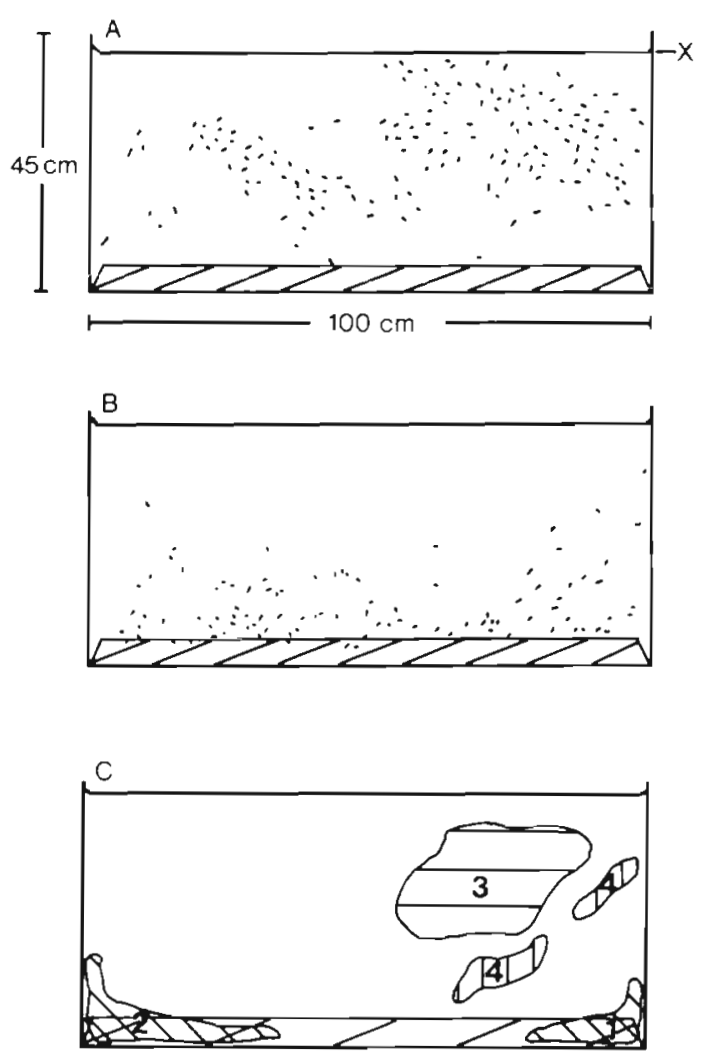

D

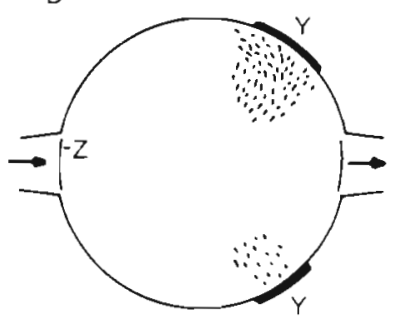

Fig. 4. Distribution of mysids in laboratory tests. (A) Normal daytime distribution of Paramesopodopsis rufa in rectangular aquaria. X: water level in aquaria. (B) Night-time distribution of $P$. rufa in rectangular aquarium. (C) Relationship in rectangular aquaria between clusters of: 1, Tenagomysis sp.; 2, Doxomysis sp.; 3, Anisomysis mixta-australis; 4, Paramesopodopsis rufa. (D) Tenagomysis sp. in the flume during substrate tests. $\mathrm{Y}$. brightly coloured areas on the walls of the flume: Z: retainers (O'Brien et al. 1986) 
of clusters taken during escape and fright reactions showed that individuals continually changed positions. (5) During darkness individuals were distributed closer to the substrate (within $20 \mathrm{~cm}$; Fig. 4A, B).

\section{Anisomysis mixta-australis}

This species is distributed widely around Tasmania and up the eastern coast of Australia (Fenton 1985). Although normally associated with sand/rock unconformities it may extend its distribution over the sand under calmer conditions to as far as 2 to $3 \mathrm{~m}$ away from the discontinuity, and was also found within Zostera sp. beds, situated over small patches of sand amongst thick beds of the seagrass. Clusters of this species were always found in the open water above the discontinuity. This species did not occupy well-defined regions above the substrate for as long as Paramesopodopsis rufa, possibly because its size and/or distribution above the substrate rendered it more vulnerable to wave action. This was especially noticeable the day after storms when $A$. mixta-australis was difficult to locate; clusters were spread out over a wider area and were markedly reduced in size. Small clusters were ovoid tending towards spherical, whereas larger clusters exhibited greater variation in morphology. This variation was dependent upon the relief of the substrate during undisturbed conditions, when aggregations tend to be amorphous (Fig. 3E), with the vertical axis becoming more compressed relative to the other axes as cluster size increased. Juvenile clusters were located closer to the substrate and were frequently found around the same discontinuities as the adults.

In the field or laboratory Anisomysis mixta-australis always formed highly polarized clusters (Fig. 3D), using even the smallest currents and variations in light regime for orientation. Variations in light regime refer to boundaries of changes in light intensity, i.e. shadows. Swarming (non-alignment of individuals) was never observed in the field and was only produced under absolutely still conditions in an aquarium in the laboratory.

Larger numbers of individuals in the flume or rectangular aquaria formed highly polarized clusters in regions of low water velocity (Fig. 3A). Clusters broke up with increased current (>15 $\mathrm{cm} \mathrm{s}^{-1}$ approx.), and disturbance by predator models or a hand passed over the tank caused relocation of individuals to another region of the aquarium. This 'avoidance' behaviour was also noted in the field, lasting for up to $5 \mathrm{~min}$ after disturbance; however, in the field the clusters returned to their previous distribution, whereas in the laboratory the change was often permanent, lasting until the next disturbance. As with Paramesopodopsis rufa, Anisomysis mixta-australis was attracted to clumps of algae in otherwise bare aquaria and clustered 3 to $10 \mathrm{~cm}$ above the algae. Cluster integrity was maintained over extended periods in the laboratory $(>5 d)$, with small schools (e.g. formed during predator avoidance) being transient in nature which usually sought to rejoin larger schools/swarms.

In the dark under laboratory conditions Anisomysis mixta-australis was relatively inactive and lay on the substrate or amongst clumps of algae. In the field the majority of individuals were spread through the water column from within the algae to $2 \mathrm{~m}$ above the substrate. The overall reduction of polarization gave the impression that the individuals were more widely spaced than during daylight; however, areas rich in the species and those devoid of it were clearly delineated during darkness, suggesting some integration of individuals with regard to movement and distribution. Individuals lying amongst the algae were attracted in large numbers to any light source within 5 to $10 \mathrm{~s}$.

\section{Tenagomysis $\mathrm{sp}$.}

Tenagomysis sp. is found all along the east coast of Tasmania (Fenton 1985) at normally sheltered sites with Paramesopodopsis rufa and Anisomysis mixta-australis, or in the wave-splash zone of sandy beaches. Tenagomysis sp. was always associated with sandy substrates, whether in depressions around rock outcrops, or during relatively still conditions over larger areas of the wave-rippled sub-littoral. Tenagomysis sp. and $A$. mixta-australis were regularly found over the same depressions and sand outcrops, and were usually only separated by their relative attraction to the substrate. Juvenile clusters were found closer to the substrate and separate to adult clusters. In certain cases this species was found to inhabit the same area (depression) for over a year. All clusters were compressed along their vertical axes and when maintaining position in wavefurrowed regions their horizontal axes were defined by the boundaries of the furrows. During calmer conditions and over sand, clusters extended their distribution as far as $5 \mathrm{~m}$ out from the furrow or unconformity. Tenagomysis sp. also formed continuous distributions $(>30 \mathrm{~m}$, width 2 to $3 \mathrm{~m}$, depth $20 \mathrm{~cm}$ ) along offshore reefs and extended rock outcrops.

Individuals were polarized in water current, orienting into the flow (Fig. $4 \mathrm{C}$ ). Clusters restricted to the waveaffected subtidal zone had a continually reversing axis of polarity into the prevailing waves or tidal current. Cluster height above the substrate was related to water velocity with a maximum extension in height above the sea floor occurring during moderate water current vel- 
ocities (10 to $15 \mathrm{~cm} \mathrm{~s}^{-1}$ ). With a departure (lower or higher) from these velocities, an increasing proportion of individuals became attached to the substrate, although the proportion of polarized individuals in the cluster still increased with increased current velocity.

In the dark Tenagomysis sp. retained the same general distribution and polarization as during daylight but was less active with individuals either clamping (settling) down onto, or swimming close to the substrate. Increased activity was triggered by shining a light on the individuals for $>5 \mathrm{~s}$. During the evening clustering behaviour persisted until after the light intensity decreased to such an extent that further direct observations could not be made without artificial illumination.

In the laboratory, features of clustering behaviour included the following: (1) A minimum number of individuals $(>100)$ was needed for an integrated cluster to form (Fig. 3A), depending on the dimensions of the tank. This suggested that the integration of individuals may be density dependent. (2) In calm conditions individuals tended to clamp down onto the bottom of the aquarium and cease swimming. In rectangular aquaria individuals always clustered in the comers (Fig. 4C). (3) In any current, Tenagomysis sp. formed highly polarized clusters in which the individuals extended up to $10 \mathrm{~cm}$ above the substrate. Individuals usually maintained a constant position within the cluster for extended periods (>1 min). Continual disturbance of a cluster (i.e. once every 5 to $10 \mathrm{~s}$ ) led to a change in distribution of individuals in the aquarium, with a gradual return to the original distribution after $>2$ min. Individuals from the front of the cluster did not necessarily remain there during the change in position suggesting that, although individuals kept a relatively stable position in current compared to calm conditions, there was still no evidence for leadership within the clusters. (4) Tenagomysis sp. showed no attraction to clumps of algae in aquaria; however, it was strongly attracted to colour discontinuities on the sides of aquaria (Fig. 4D). Qualitatively, no overall difference in clustering behaviour was found over different coloured or textured substrates. (5) In the dark this species was inactive and lay on the substrate, with the individuals being spread out over a wider area of the floor of the aquarium.

\section{Doxomysis sp.}

Clusters were always associated with depressions and furrows in rocky substrates or gaps between algae growing on the substrate. Whereas Tenagomysis sp. dominated shallow gently sloping areas, Doxomysis sp. dominated deeper regions especially in rocky areas. Two types of cluster were observed: those in which there was a wide size range of individuals, resembling small 'family units' (Fig. 3F); and larger, relatively unimodal clusters found in larger depressions or gaps between obstructions during calmer conditions. Doxomysis $\mathrm{sp}$. showed the same distribution relative to the substrate as Tenagomysis sp. and general cluster morphology was also dictated by substrate relief and water flow. This species also occupied the same depression for extended periods ( $>1 \mathrm{yr}$; pers. obs. at Tinderbox).

Movement of individuals was highly integrated, with water current causing polarization and disturbance causing an integrated escape response. Within clusters the movement of individuals was similar to that described for Paramesopodopsis rufa.

Laboratory observations of Doxomysis sp. demonstrated the similarity between the clustering habits of this species and of Tenagomysis $\mathrm{sp}$. Both aggregated in the corners of rectangular aquaria (Fig. 4 C) and around the edges of the flume, occasionally forming multispecific clusters in the corners of the aquarium when present at high densities. After rough sea conditions, mixed clusters were also found in the field in regions where their distributions overlapped. In the flume Doxomysis sp. was nearly always restricted to the edges and showed an attraction to regions of increased light intensity after acclimation to the new light regime. Unlike Tenagomysis sp. it was not attracted to colour unconformities along the sides of the flume.

\section{Australerythrops paradicei}

This species was observed on only 2 occasions during visits to submarine caves off the southeast coast of Tasmania (Fig. 1). It was found around the entrance to a cave extending a few metres into the cave itself, at depths from 8 to $12 \mathrm{~m}$. Clusters were reminiscent of large polarized clusters of Paramesopodopsis rufa juveniles, the mysids being very similar in both colour and attraction to the substrate. They faced into the current as it ebbed and flowed through the cave and showed a highly integrated response when reversing direction and avoiding divers. In the laboratory Australerythrops paradicei formed dense, highly integrated clusters in which the margins were more clearly delineated than for any of the previous species (Fig. 3G). The individuals generally oriented into the main flow of current through the centre of the flume up to velocities of approximately $10 \mathrm{~cm} \mathrm{~s}^{-1}$.

\section{Tasmanomysis oculata}

Tasmanomysis oculata was rarely observed (on only 2 occasions in $>50$ dives at Taroona Beach). It was always observed in highly polarized clusters, whose 
character differed depending on the site of observation. At Taroona Beach this species was found over the sand substrate at a depth of 0.5 to $3 \mathrm{~m}$ (in the surf zone). In this area the mysid was transparent and formed polarized clusters with inter-individual distances (estimated by diver) of $>2$ body lengths. At Adventure Bay T. oculata was located on 2 occasions at depths of 2 to $3 \mathrm{~m}$ over red and brown algal beds and formed highly compact, polarized clusters with inter-individual distances of approximately 1 bodylength or less (Fig. $4 \mathrm{H}$ ). At this latter site the individuals were all deep brown. The clusters were all discoid with a flattened vertical axis, with cluster size being smaller in the surf zone at Taroona Beach in comparison to the calmer waters of Adventure Bay. In the laboratory, polarized clusters formed in currents with the individuals always located near unconformities such as stones or algal clumps; a high degree of polarization was maintained even during calm conditions.

\section{DISCUSSION}

The results of the present study are in agreement with the findings of Zelickman (1974) who concluded from a study on swarming behaviour in Neomysis mirabilis that: 'aggregations are controlled by biological mechanisms; hydrological processes only create a background favourable to their formation'. Evidence derived from the present study for the intrinsic character of cluster formation in mysids includes the following: (1) Although clusters demonstrate the capacity to modify their internal organisation and external morphology according to extrinsic influences (e.g. water current, light regime, predation), the absence of any one of these influences is not sufficient in itself to prevent cluster formation or persistence. (2) Cluster integrity is maintained at least in part by gregariousness, e.g. turning of individuals at the edge of the cluster back into the main body. (3) There was no evidence for any of these species having a solitary phase in its life history. (4) All species generally formed monospecific clusters and were segregated in size/age classes. (5) The rapid formation of monospecific clusters capable of integrated responses to changes in extrinsic factors, and the observed co-ordination between individuals during antipredator responses (O'Brien \& Ritz in press) demonstrate the high degree of integration between clustering individuals. (6) Young are released as juveniles capable of swimming and able to maintain their own position within the environment.

Wittman (1976) proposed that swarm cohesion is controlled by preference for the same habitat and probably by non-specific gregariousness. In the species involved in the present study, habitat preference may aid species segregation but it does not explain the ability of at least some of the species to migrate as cohesive units (i.e. Paramesopodopsis rufa, Tasmanomysis oculata) and relocate at different sites as described for Mysidium gracile (Hahn \& Itzkowitz 1986). Few examples of non-specific gregariousness have been documented, for example stray mysids taking cover within the boundaries of clusters of other species, or 2 species combining due to adverse conditions (in the corners of rectangular aquaria). This would suggest that species-specific gregariousness is normal in clustering species.

The basic morphology of aggregations, and adaptations for antipredation (O'Brien \& Ritz in press), are the same in those species that form clusters. Reproductive strategies are also similar; all species are reproductively active throughout the year, and maximise the contact between reproductively mature males and females by segregating size classes and maintaining high proportions of both sexes in individual clusters. Therefore, of the functions of mysid swarming (clustering) behaviour described by Clutter (1969), i.e. maintenance of position, decrease in predation and an increase in reproductive potential, it would seem that maintenance of position is probably the most important factor influencing variation in clustering behaviour. However, variations in zonation and clustering behaviour are also consistent with the competitive exclusion principle. The species range from substrateassociated to non-substrate-associated. Results provided by Fenton (1985) suggest that the diets of Anisomysis mixta-australis, Paramesopodopsis rufa and Tenagomysis sp. are related to their proximity to the substrate and that there is some degree of resource partitioning between the three. This variation in diet is probably related to the need to reduce inter-specific competition for food and space, with Anisomysis mixtaaustralis and Tenagomysis sp. being separated on the basis of particle size, and Paramesopodopsis rufa differing from the others in having a larger proportion of pelagically derived prey in its diet (Fenton 1985). Clutter (1967) also came to the conclusion that mysid zonation was a manifestation of competitive exclusion and that it entailed apparent competition for space rather than food. Separation in space in clustering species is manifested in the varying degree of substrate attraction, and selection pressure is probably primarily produced by the differences in hydrography, with secondary pressures including feeding and antipredation. The various forms of these adaptations shown by species in the present study included: (1) maximisation of the numbers of individuals of the species in a favourable area (Tenagomysis sp., Anisomysis mixta-australis, Australerythrops paradicel), thereby reducing the 
effects of transportation due to adverse water currents or concentrated predation pressure; (2) behaviourally induced avoidance of being transported away from the area and conspecifics (clamping down to the substrate, Tenagomysis sp., Doxomysis sp.); (3) inhabiting regions offering shelter from currents (depressions in the substrate or gaps between algal fronds, Doxomysis sp., Paramesopodopsis rufa). In Doxomysis sp. there was evidence for mixed adult/juvenile clusters, produced possibly due to competition for space in small sheltered recesses and/or in response to isolation from other suitable substrates. This would be likely to produce cannibalism especially if food was also limiting; however, as proposed by Clutter (1969), cannibalism may be a mechanism involved in the self-regulation of the population in such confined spaces; (4) development of larger body size and increased swimming capabilities in species with low substrate attraction (allowing resistance to excessive wave shear during rough sea conditions and/or migration to calmer areas, Paramesopodopsis rufa, Tasmanomysis oculata). Clutter (1967) also foreshadowed this idea with his observation that larger mysids can live closer to shore.

Clutter (1969) proposed that the probable primary stimuli involved in swarm (cluster) maintenance are visual cues initiated during daylight, a view supported by the findings of Macquart-Moulin (1973). The evidence from the present study supports this interpretation with cluster integrity decreasing during darkness in the more pelagic species, i.e. Paramesopodopsis rufa, Anisomysis mixta-australis. The method for retaining the same approximate distribution and cluster integration at night, albeit at a lower level, would seem to be related to either a decrease in general activity with the mysids sinking to the seafloor or an increased attraction to the substrate.

There was some evidence from the laboratory experiments for there being a critical density for school formation in substrate specialists (Doxomysis sp. and Tenagomysis sp.), as suggested by Steven (1961), but this was not found to be the case for the pelagic species (Paramesopodopsis rufa and Tasmanomysis oculata).

On the basis of Wittman's (1976) spectrum of swarm to substrate-specialists, the 6 species studied would be classified broadly as swarm (cluster) specialists, with Tenagomysis sp. and Doxomysis sp. falling in his D or E categories, and the remainder being categorised in $\mathrm{F}$. However, when evaluated in the light of the behavioural ecology of the species described in the present study, Wittman's spectrum becomes confusing. His creation of a distinction between substrate and swarm specialists precludes the close association of swarm specialists to particular substrate types or topography, as is seen in Doxomysis sp. and Tenagomysis sp. Mauchline's classification (1971) combines descrip- tions of mysid aggregations, based on their basically transient morphology (both internal and external), with a preliminary attempt to define the aggregations according to the mechanisms stimulating their formation and maintenance. However, he restricts the scope of the definitions to mating (termed breeding aggregation), and the premise that a restricted distribution in a defined area is probably due to environmental parameters rather than behavioural responses. Wittman's (1976) attempt to redefine certain terms employed by Mauchline only addressed those terms describing aggregations by their morphology, i.e. schools, swarms.

In Fig. 5 I propose a simple classification of mysid aggregations based on the mechanisms responsible for their formation and maintenance. The classification assumes a relatively comprehensive knowledge of the behavioural ecology of the species concerned and also indicates the relationship between definitions based on the morphological character of the aggregations and the mechanisms influencing swarm formation. The possibility of extending the terminology describing zooplankton aggregations was foreshadowed in a review by Omori \& Hamner (1982) on the patchy distribution of zooplankton in which they make the prophetic statement in reference to definitions suggested by Mauchline (1980) that ... if we are too concerned with the terms themselves, we will tend to search for observations that match the definitions'. This statement became especially pertinent to the present study when it was realised that the observed mysid aggregations were not breeding swarms nor simply restricted in their distribution and that to describe them in terms of their morphological structure would have necessitated the use of a term such as 'swarm/school/ shoal' due to the plastic nature of the internal/external form of the aggregations.

In the present classification I have endeavoured, where possible, to include terminology previously suggested by Mauchline (1971); however, I suggest the use of the term 'cluster' to define aggregations of species in which individuals of all stages (although generally segregated) are distributed in integrated aggregations at least during daylight in response to internal biological mechanisms. Cluster does not connote any particular internal or external morphology as could possibly be surmised by the terms swarm, school and shoal.

The scheme may also have wider application in describing the function of aggregative behaviour in a range of planktonic and nectonic invertebrates (and vertebrates?). To my knowledge there are at present no definite examples of passive aggregations within the Mysidacea; however, mechanisms have already been described for the formation of this type of aggregation in a variety of species of zooplankton and micronekton 


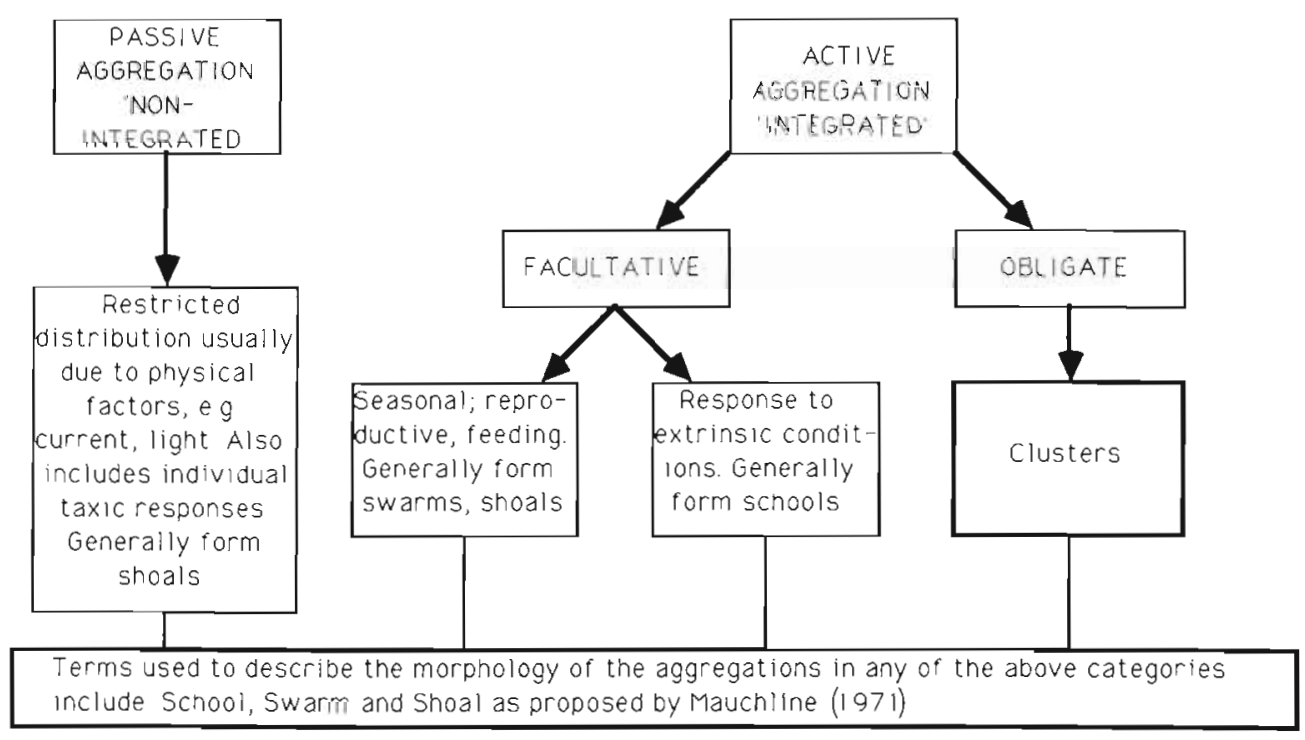

Fig. 5. Classification of mysid aggregations in relation to mechanisms influencing their formation and maintenance. Terms describing the morphology of aggregations are as defined by Mauchline (1971)

(e.g. Haury et al. 1978, Alldredge \& Hamner 1980). Furthermore, it is probable that for planktonic aggregations, passive mechanisms may be the most prevalent agent in their formation. Actively formed aggregations refer primarily to those produced in response to socially induced mechanisms. Social groups may be divided into those species in which the individuals spend all of their lives in aggregations, as exemplified by the mysids described in the present study, and those formed on an irregular (temporal) basis using either intrinsic or extrinsic influences as their cue(s). The former species may be termed obligate and the latter facultative, using terminology defined by Breder (1967) with respect to fish schools. Examples of facultative aggregations include Mysis gaspensis formed in response to tidal flow regime in an estuary (Dadswell 1975), and the crab larvae Munida gregaria (Zeldis \& Jillett 1982, Jillett \& Zeldis 1985) whose shoals form possibly as a result of both intrinsic (migration, dispersion) and extrinsic (internal waves) factors. Examples of intrinsically formed aggregations of euphausiids can be found in e.g. Komaki (1967) and Nicol (1984), and are generally but not always reproductive in nature. Morphologically descriptive terms are included to aid visualisation of the relationship between form and the mechanisms precipitating swarm formation. As already intimated form does not describe function and the whole array of morphological terms could apply to any one class of aggregation described in the scheme. I propose that only lack of available data describing the aggregative ethology of representatives of the zooplankton and/or micronekton, has hindered progress towards such a scheme.
Acknowledgements. I thank Dr Gwen Fenton of the Zoology Department, University of Tasmania for her help and discussion of general mysid biology throughout the course of the study, and Drs David Ritz and Roy Swain for their critical appraisal of the manuscript and helpful advice.

\section{LITERATURE CITED}

Alldredge, A. L., Hamnex, W. M. (1980). Recurring aggregation of zooplankton by tidal current. Estuar. coast. mar. Sci. 10: 31-37

Breder, C. M., Jr (1967). On the survival value of fish schools. Zoologica 52: 25-40

Clutter, R. I. (1967). Zonation of nearshore mysids. Ecology 48: 200-208

Clutter, R. I. (1969). The microdistribution and social behaviour of some pelagic mysid shrimps. J. exp. mar. Biol. Ecol. 3: 125-155

Dadswell, M. J. (1975). Some notes on shoaling behaviour and growth of Mysis gaspensis (Mysidacea) in a small Newfoundland estuary. Can. J. Zool. 53: 374-377

Fenton, G. E. (1985). Ecology and taxonomy of mysids (Mysidacea: Crustacea). Ph.D. thesis, University of Tasmania

Hahn, P., Itzkowitz, M. (1986). Site preference and homing behaviour in the mysid shrimp Mysidium gracile (Dana). Crustaceana 51: 215-219

Haury, L. R., McGowan, J. A., Wiebe, P. H. (1978). Patterns and processes in the time space scales of plankton distribution. In: Steele, J. (ed.) Spatial patterns in plankton communities. Plenum Press, New York, p. 277-327

Jillett, J. B., Zeldis, J. R. (1985). Aerial observations of surface patchiness of a planktonic crustacean. Bull. mar. Sci. 37; 609-619

Komaki, Y. (1967). On the surface swarming of euphausiid crustaceans. Pacif. Sci. 21: 433-448

Macquart-Moulin, C. (1973). Le comportement d'essaim chez les Mysidaces. Influence de l'intensité lumineuse sur la formation, le maintien et la dissociation des essaims de 
Jillett, J. B., Zeldis, J. R. (1985). Aerial observations of surface patchiness of a planktonic crustacean. Bull. mar. Sci. 37: 609-619

Komaki, Y (1967). On the surface swarming of euphausiid crustaceans. Pacif. Sci. 21: 433-448

Macquart-Moulin, C. (1973). Le comportement d'essaim chez les Mysidaces. Influence de l'intensité lumineuse sur la formation, le maintien et la dissociation des essaims de Leptomysis linguura. Rapp. P.-v, Réun. Commn int. Explor. scient. Mer Méditerr. 21: 499-501

Mauchline, J. (1971). Seasonal occurrence of mysids (Crustacea) and evidence of social behaviour. J. mar. biol. Ass. U.K. 51: 809-825

Mauchline, J. (1980). Studies on patches of krill, Euphausia superba Dana. BIOMASS Handb. 6: 1-36

Nicol, S. (1984). Population structure of daytime surface swarms of the euphausid Meganyctiphanes norvegica in the Bay of Fundy. Mar. Ecol. Prog. Ser. 18: 241-251

O'Brien, D. P. (1987). Gregarious behaviour in crustacean micronekton (Euphausiacea, Mysidacea). Ph.D. thesis, University of Tasmania

O'Brien, D. P., Ritz, D. A. (in press). Escape responses of gregarious mysids (Crustacea: Mysidacea): towards a general classification of escape responses in aggregated crustaceans. J. exp. mar Biol. Ecol

O'Brien, D. P., Tay, D., Zwart. P. W (1986). A laboratory method of analysis of swarming behaviour in the macroplankton: combination of a modified flume tank and stereophotographic techniques. Mar. Biol. 90: 117-127

Omori, M., Hamner, W. M. (1982). Patchy distribution of zooplankton: behaviour, population assessment and sampling problems. Mar. Biol. 72: 193-200

Steven, D. M. (1961). Shoaling behaviour in a mysid. Nature, Lond. 192: 280-281

Wittman, K. J. (1976). Modification of association and swarming in North Adriatic Mysidacea in relation to habitat and interacting species. In: Keegan, B. F., O'Ceidigh, P., Boaden, P. J. S. (eds.) Biology of benthic organisms. Pergamon Press, Oxford, p. 605-612

Zeldis, J. R., Jillett, J. B. (1982). Aggregation of pelagic Munida gregaria (Fabricius) (Decapoda, Anomura) by coastal fronts and internal waves. J. Plankton Res. 4: 839-857

Zelickman, E. A (1974). Group orientation in Neomysis mirabilis (Mysidacea: Crustacea). Mar. Biol. 24: 251-258

This article was submitted to the editor; it was accepted for printing on November 30,1987 